\title{
THE ROLE OF NEGATIVE AFFECTIVITY AND INCIVILITY BEHAVIOR ON INCIDENCE OF COUNTERPRODUCTIVE WORKPLACE BEHAVIOR AMONG NURSES \\ ${ }^{1}$ Noura Atef Elsayed, ${ }^{2}$ wafaa Fathi Sleem,${ }^{3}$ Eltahra El-Sayed Abo Habieb \\ 1,2, 3 Department of Nursing Administration, Faculty of Nursing, Mansoura University, Egypt
}

\begin{abstract}
Background: Nowadays workplace deviant behaviors considered one amongst the foremost serious issues facing today's organizations and its productivity as it goes against the legitimate interests of the organization. These behaviors can harm organizations or people in organizations. So, the study aimed to determine role of negative affectivity and workplace incivility on incidence of counterproductive work place behavior among nurses at Main Mansoura University Hospital. Method: A descriptive design was used and the study was conducted on 162 nursing staff working at Main Mansoura University hospital by using three tools as: Negative Affectivity questionnaire, workplace incivility questionnaire and counterproductive workplace behavior questionnaire. Results: the mean score of counterproductive workplace behavior is lowest $(1.23 \pm 0.26)$ followed by workplace incivility $(1.32 \pm 0.35)$ and negative affectivity(1.89 \pm 0.78$)$. There was statistically significant positive correlation between counterproductive workplace behavior and both negative affectivity and workplace incivility $(\mathrm{P}<0.05)$ among nursing staff $(\mathrm{n}=162)$. Recommendation: design and implement policies to reduce the deviant behaviors in the hospital environment. Organizations need to adopt zero tolerance policies that clearly articulate the types of conduct are not acceptable. These policies need to be clearly defined and communicated to all in the hospital and all who enter. There needs to be channels for employees to communicate issues. There also needs to be commitment to upholding these policies from top management.
\end{abstract}

Keywords: Counterproductive Workplace Behavior, Negative Affectivity, Workplace Incivility

\section{Introduction:}

Recently there are various types of workplace violence and stressful situation that produce negative effects on both nurses and organizations, that lead to aggressive behaviors ranging from physical violence to psychological aggression, all of which produce negative affectivity at workplace, this negative affectivity affect productivity and encourage deviant behaviors at workplace called incivility behavior .Negative affectivity and workplace incivility appears to be a significant precursor of counterproductive work place behavior $(\mathrm{CWB})^{(\mathbf{1})}$.

Negative affectivity is temperament attribute that predisposes to cluster of negative emotions as a psychological risk issues ,include anger, disgust, guilt, fear (2) . Negative affectivity in the workplace can be caused by work overload, lack of rewards, and social relations (3). Nurses who express high negative affectivity view themselves and a variety of aspects of the world around them in generally negative terms, they exhibit higher levels of distress, anxiety, and dissatisfaction, and tend to focus on the unpleasant aspects of themselves, the world, the future, and other people, also they evoke more negative life events, and tend to perceive things through black lens ${ }^{(4)}$. In contrast to nurses with high positive affectivity tend to perceive 
things through pink lens, and characterized by frequent states of calmness and serenity, along with states of confidence, activeness and great enthusiasm (5). So that, nurses with high negative affect have larger motivation to interact in behaviors that they believe can facilitate them cope with these negative emotions and engage in workplace incivility behaviors that harm both employee and organization (6).

Workplace incivility has been considered as an important workplace stressor and has been linked to various negative outcomes, it has been mostly treated as a chronic stressor ${ }^{(7)}$

.Workplace

incivility is defined as" low intensity deviant behaviour with ambiguous intent to harm the target, in violation of workplace norms for mutual respect ${ }^{(8)}$. On other hand, workplace incivility have a negative effect on many organizational outcomes such as employee performance, reduction in productivity, organizational commitment, job commitment, job satisfaction, and organizational trust ${ }^{(9)}$. So that nurses who experience workplace incivility behaviors are more likely to interact in CWB.

CWB represent one of the most serious issues confronting today's organizations in many countries (10). CWB is commonly defined as employee action that violates organizational norms which can harm organizational well-being and its members including the clients, customers, supervisors or co-workers such as sabotage, theft and wasting organizational source (11). Also include acts like direct aggression, intentionally failing to follow directions or to perform work incorrectly, within the interest of violating important organizational norms reducing the potency and job performance of its members ${ }^{(12)}$.

The antecedents of CWB that lead to behaviors include two factors both situational and personal factors. Situational factors considered are job stressors, any frustrating condition in structure life intrusive with goals and job performance increase the probability to act CWB. Whenever such stressors occur, people could experience negative emotions which can successively , promote individuals to enact aggressive behavior as a technique to diminish the emotionally unpleasant condition ${ }^{(13)}$.

All CWB are divided into 2 classes, one toward organizations and another toward individuals within the organizations ,CWB directed towards organization (CWB-O) target the organizations, they're acts like sabotage, fraud and stealing or leaving early from work, taking excessive breaks, deliberately operating slowly, wasting resources then on, CWB towards individuals within the organizations(CWB-P) are acts completely directed to individuals operating within organizations like sexual harassment, verbal abuse, stealing among colleagues and even selecting favorites and insulting colleagues ${ }^{(14)}$.

CWB, negative affectivity and workplace incivility is thus offered through the model of ( job -stress process) that view employees who have job stressors ,that lead to affective reactions, such as negative affectivity which in turn lead to abnormal behaviors in the form of workplace incivility behaviors, in which employees who experience this negative emotions can look for to repair their emotional state (affect management) through engagement in $\mathrm{CWB}^{(15)}$. So, this study intended to determine the role of negative affectivity and incivility behavior on incidence of counterproductive workplace behavior among nurses.

\section{Significant of the study}

Negative affectivity can be seen as a disease in workplace as well as, nurses are 
THE ROLE OF NEGATIVE AFFECTIVITY AND INCIVILITY etc...

particularly subject to stressful situations. They are increasingly subjected to urgent, heavy workloads and unfairness at workplace thus, their mood is often extremely low ${ }^{(16)}$. Prolonged exposure to this stressful situations produce negative affective emotions toward organization and encourage employees to produce incivility behaviors to cope with this stressful situations. This negative affectivity and incivility behaviors will increase workers likely to engage in counterproductive workplace behavior that go against goal of the organization and it's actual or potential harmful and damaging effects of such behaviors on each the organization and its members.

\section{Aim of the study}

The study aims to determine the role of negative affectivity and workplace incivility on incidence of counterproductive work place behavior among nurses at Main Mansoura University Hospital.

\section{Research questions:-}

Q1:What is the negative affectivity among nurses at Main Mansoura University Hospital?

Q2: What is the workplace incivility among nurses at Main Mansoura University Hospital?

Q3: What is the counterproductive workplace behavior among nurses at main Mansoura University Hospital?

Q4: There is a relation between negative affectivity and workplace incivility and their counterproductive work place behavior among nurses?

\section{III.Method}

\section{Research design:}

Descriptive design was used in this study.

\section{The study setting:}

The study was conducted at all medical and surgical department at Main Mansoura University Hospital that provide a wide spectrum of health services at Delta Region . Main Mansoura University Hospital occupied with (1800) bed and includes 16 department in addition to units attachments to the main building . Subjects of the study:

The subjects of the present study included all nursing staff working at medical and surgical department available at time of data collection in the previously mentioned settings. Their total numbers were (162) nursing staff classified as the following (126) from surgical departments and (36) from medical department.

\section{Tool of data collection:-}

Three tools were used for data collection:

Tool (1) : Negative Affectivity:

It consists of two parts as follows:

Part I: personal data: It covered items related to nursing staff as age, gender, marital status ,department, qualification, years of experience.

Part II: Negative Affectivity: This tool developed by( Watson et al., 1988) ${ }^{(17)}$. It is aimed to assess negative affectivity. It consists of 10 words from positive and negative affective schedule (PANAS) (distressed, upset, guilty, scared, hostile, irritable, ashamed, nervous, jittery \& afraid) that describe negative emotion on a 5-point Likert scale ranging from (very slightly or not at all=1 to very much $=5$ ).

Tool (2): workplace incivility: This tool was developed by (Penny and Spector $2005)^{(\mathbf{1 8})}$. It is aimed to indicate how frequently they been subjected to each of behaviors at work. It is contain (47) items, The response for the items on a 5-point. Likert scale ranging from (never $=1$ to every day $=5$ ).

\section{Tool (3): Counterproductive Work}

\section{Behavior Checklist (CWBC)}

This tool was developed by (Spector et al., 2006) ${ }^{(19)}$. It is aimed to determine how often they have done each behavior at work. It is contain (45) items, categorized into two domain, organizational counterproductive workplace behavior ( 22 items) and personal counterproductive workplace behavior (23 items ). The 
response for the items on a 5-point Likert scale ranging from (never $=1$ to every day=5 ).

\section{Validity and reliability:}

It was done via a panel of three expertise from different nursing faculty ,who reviewed the tools for clarity, relevancy, applicability, comprehensiveness, understanding, and ease for implementation and according to their opinions simple modifications were applied from the tools.

\section{Pilot study:}

A pilot study was carried out on (18) nursing staff from surgical and medical departments at Main Mansoura University hospital as $10 \%$ of the study sample.to evaluate the clarity and applicability of the tools and were excluded from the total sample, to asses reliability, the study tools was tested by the pilot subjects at first session for calculating Cronbach's Alpha reliability and was $0.894,0.879,0.899$ respectively . Ethical consideration:- Ethical approval was obtained from the research ethics committee of the Faculty of nursing Mansoura University .An official permission to conduct the study was obtained from hospital authorities. Prior to the initial interview, explanation of the aim and the nature of the study were performed by the researcher to all nursing staff included in the study. Also, a verbal consent was obtained from each participant before participation in the study. The researcher emphasized that the participation is absolutely confidential and voluntary as of the subjects' privacy is absolutely assured through the entire study.

\section{Statistical analyzing :}

The collected data were arranged, tabulated as well statistically analyzed via SPSS software (Statistical Package for the Social Sciences, version 19, SPSS Inc. Chicago, IL, USA). For quantitative data, the mean, range, as well standard deviation were calculated. Comparison among the two groups as well more was performed by using Chi-square test $\left(\chi^{2}\right)$ for qualitative data.

\section{Results:}

Table (1): show personal characteristic of nursing staff .According to age, most of them $(55.6 \%)$ were $21-<30$ years old. As regarding gender $(90 \%)$ were female. More than half of them $(64.8 \%)$ were married . As for educational level (65.4\%) had diploma of technical nursing institute while $(18.5 \%)$ had diploma and $(16.0 \%)$ had bachelor. In addition $(65.8 \%)$ had 1$<10$ experience years ,while $(12.3 \%)$ had 20-35 experience years. Finally the majority $(77.8 \%)$ were working in surgical unit .

Table (2): show mean scores of negative affectivity ,workplace incivility among studied nursing staff . According to this table mean score of negative affectivity was $(1.89 \pm 0.78)$ while mean score of workplace incivility was (1.32 \pm 0.35$)$.

figure(1) : show mean score of counterproductive workplace behaviors (CWB) (organizational and personal) among the studied nursing staff . According to this table the mean score of organizational CWB was higher than personal CWB with mean score (1.27士0.30).

Figure (2): show Correlation between organizational counterproductive workplace behaviors (CWB) scores and both negative affectivity scores and work place incivility scores among the studied nursing staff. According to this figure , there was statistically significant positive correlation between organizational CWB and both negative affectivity and workplace incivility $(\mathrm{p}<$ 0.0001).

Figure (3): show Correlation between personal counterproductive workplace behaviors (CWB) scores and both negative affectivity scores and work place incivility scores among the studied nursing staff. 
THE ROLE OF NEGATIVE AFFECTIVITY AND INCIVILITY etc...

According to this figure, there was statistically significant positive correlation between personal CWB and both negative affectivity and workplace incivility $(\mathrm{p}<0.0001)$.

Figure (4): show Correlation between total counterproductive workplace behaviors (CWB) scores and both negative affectivity scores and work place incivility scores among the studied nursing staff. According to this figure, there was statistically significant positive correlation between total CWB and both negative affectivity and workplace incivility $(\mathrm{p}<0.0001)$.

Table (1): personal characteristic data of the studied nursing staff $(n=162)$.

\begin{tabular}{|c|c|c|}
\hline \multirow{2}{*}{ Variables } & \multicolumn{2}{|c|}{ The studied nursing staff $(n=162)$} \\
\hline & $\mathbf{N}$ & $\%$ \\
\hline \multicolumn{3}{|l|}{ Age years: } \\
\hline $21-<30$ & 90 & 55.6 \\
\hline $30-<40$ & 50 & 30.9 \\
\hline $40-55$ & 22 & 13.6 \\
\hline $\begin{array}{l}\text { Range } \\
\text { Mean } \pm S D\end{array}$ & \multicolumn{2}{|c|}{$\begin{array}{l}21.00-55.00 \\
29.52 \pm 7.32\end{array}$} \\
\hline \multicolumn{3}{|l|}{ Gender: } \\
\hline Male & 16 & 9.9 \\
\hline Female & 146 & 90.1 \\
\hline \multicolumn{3}{|l|}{ Marital status: } \\
\hline Married & 105 & 64.8 \\
\hline Single & 57 & 35.2 \\
\hline \multicolumn{3}{|l|}{ Educational level } \\
\hline Diplome & 30 & 18.5 \\
\hline Diploma of technical nursing institute & 106 & 65.4 \\
\hline Bachelor degree & 26 & 16.0 \\
\hline \multicolumn{3}{|l|}{ Experience years: } \\
\hline $1-<10$ & 92 & 56.8 \\
\hline $10-<20$ & 50 & 30.9 \\
\hline $20-35$ & 20 & 12.3 \\
\hline Range & \multirow{2}{*}{\multicolumn{2}{|c|}{$\begin{array}{l}1.00-35.00 \\
9.67 \pm 7.31\end{array}$}} \\
\hline Mean \pm SD & & \\
\hline \multicolumn{3}{|l|}{ Work department: } \\
\hline Medical unit & 36 & 22.2 \\
\hline Surgical unit & 126 & 77.8 \\
\hline
\end{tabular}

Table (2): Mean scores of negative affectivity, work place incivility among the studied nursing staff $(\mathrm{n}=162)$.

\begin{tabular}{|c|c|c|}
\hline \multirow{2}{*}{ Variables } & \multicolumn{2}{|c|}{ The studied nursing staff (n=162) } \\
\cline { 2 - 3 } & Range & $\begin{array}{c}\text { Mean } \pm \text { SD/No. of } \\
\text { questions }\end{array}$ \\
\hline Negative affectivity scores & $10-50$ & $1.89 \pm 0.78$ \\
\hline Work place incivility & $44-129$ & $1.32 \pm 0.35$ \\
\hline
\end{tabular}




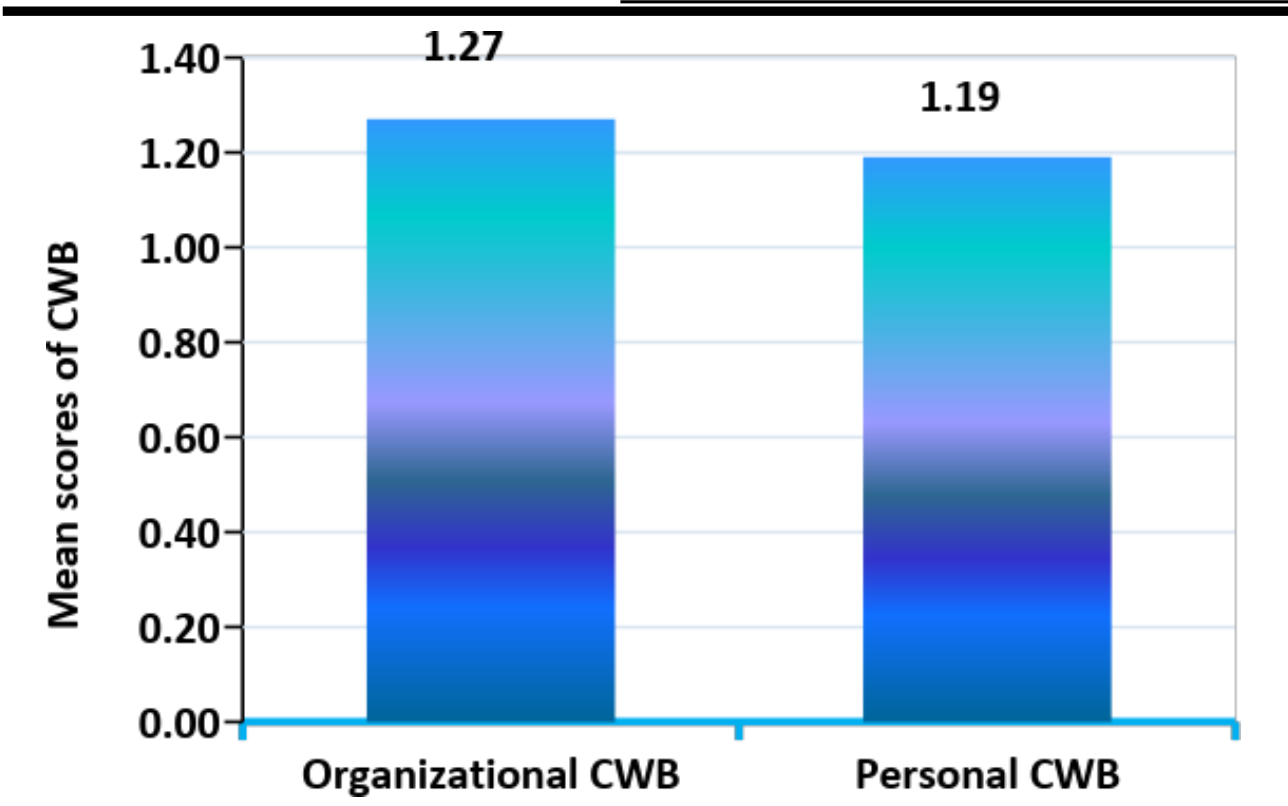

Figure (1): Counterproductive workplace behaviors (CWB) (organizational and personal) scores among the studied nursing staff $(n=162)$.

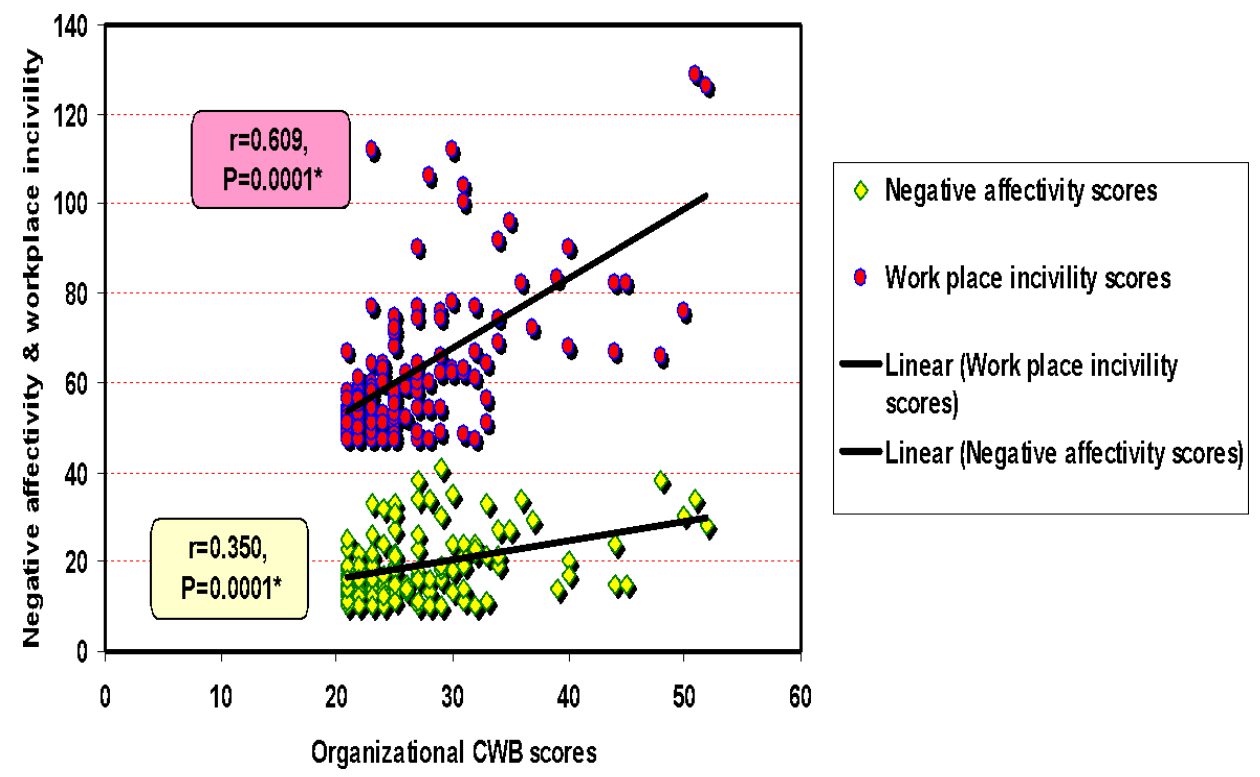

Figure (2): Correlation between organizational counterproductive workplace behaviors (CWB) scores and both negative affectivity scores and work place incivility scores among the studied nursing staff $(n=162)$. 


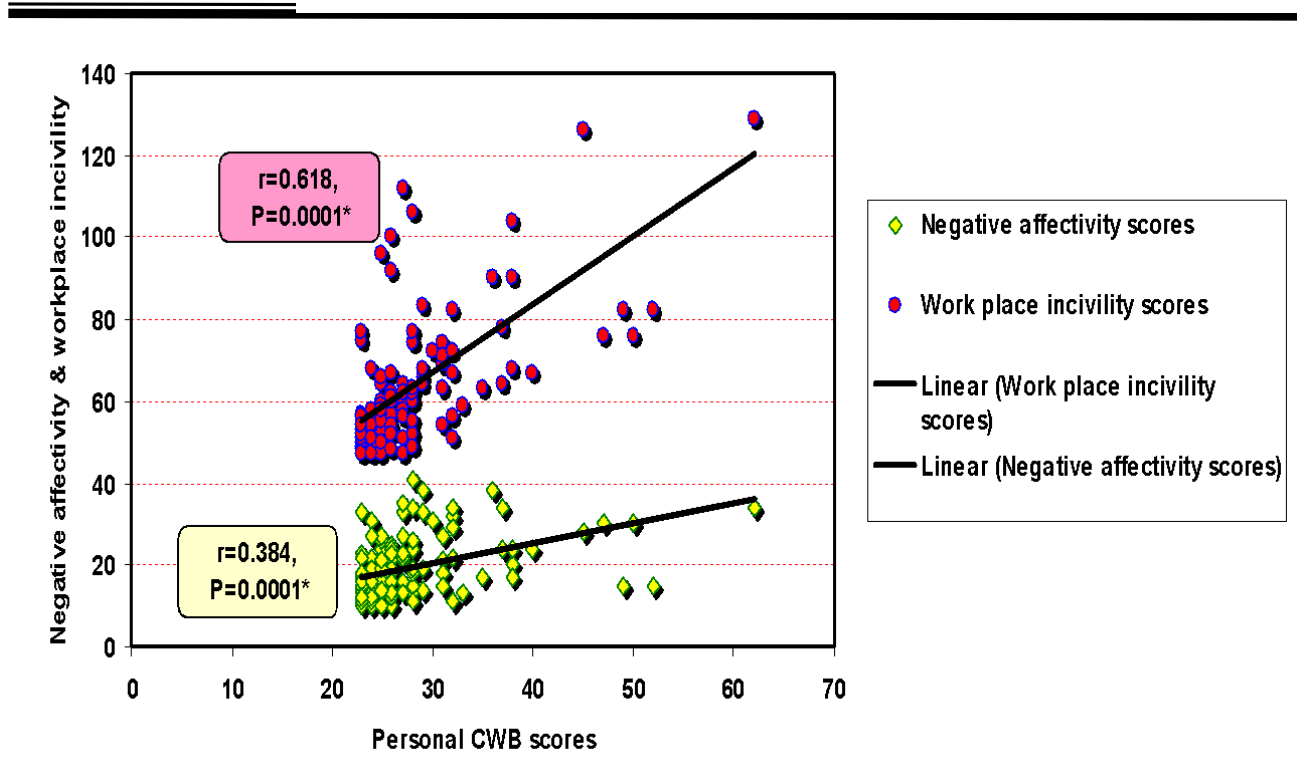

Figure (3): Correlation between personal counterproductive workplace behaviors (CWB) scores and both negative affectivity scores and work place incivility scores among the studied nursing staff $(\mathrm{n}=162)$.

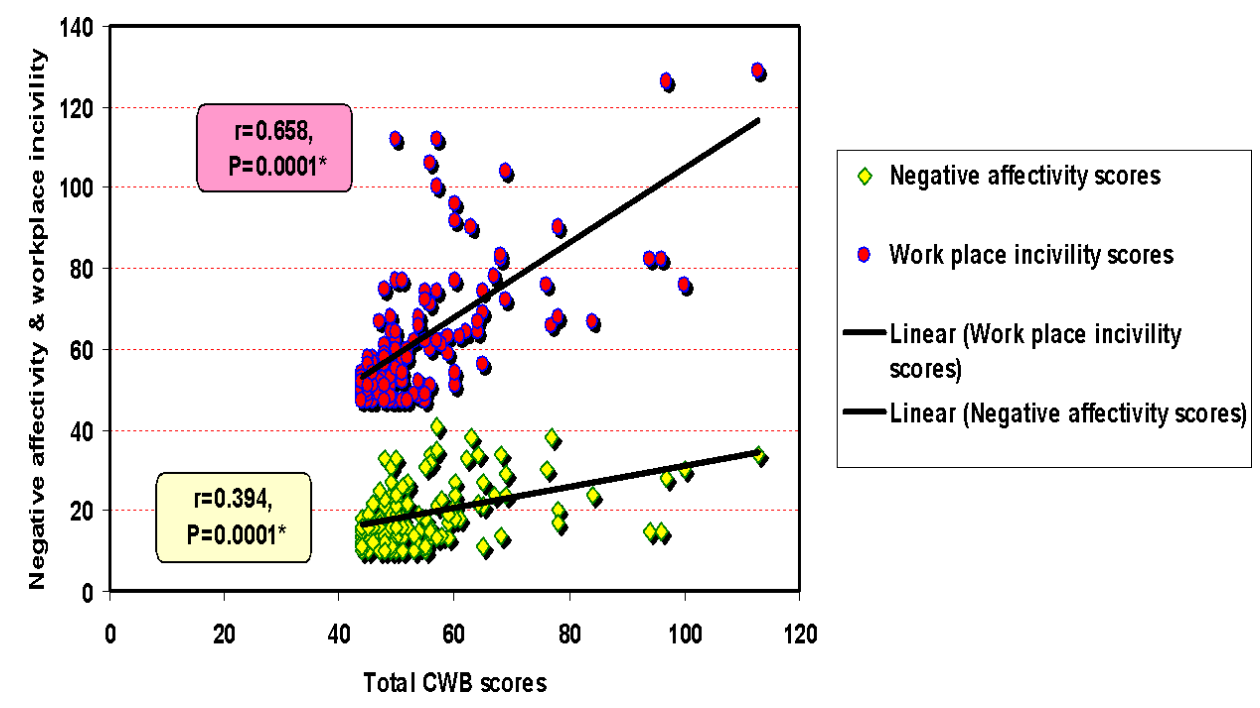

Figure (4): Correlation between total counterproductive workplace behaviors (CWB) scores and both negative affectivity scores and work place incivility scores among the studied nursing staff $(n=162)$. 
Discussion

Technological advancement and globalisation and present day work force has become far more diverse. Individuals with totally different backgrounds, attitudes and personalities understand a similar event differently and these variations cause conflicts that have their implications at work, like developing negative affect toward workplace .This negative affectivity affect encourage deviant behaviors at workplace one of them is incivility behavior .This negative affectivity and workplace incivility seems to be a major precursor of counterproductive work place behavior (CWB). CWBs are such harmful and intentional acts that are directed towards damaging the set goals, and resources of an organization systems or its members (Dilchert, Ones, Davis \&Rostow, 2007) (20).

The present study aims to determine role of negative affectivity and workplace incivility on incidence of counterproductive work place behavior among nurses through assessing nursing staff negative affectivity, workplace incivility and counterproductive workplace behavior and detecting relation between negative affectivity, workplace incivility and counterproductive workplace behavior.

The study results revealed that the mean score of total counterproductive workplace behavior is low (low level of occurrence) it may be due to nursing staff fear from hospital sanctions as decrease in salary or punishment shift and respecting of nursing staff to hospital policy. So that, majority of nursing staff never engage in the following behaviors as purposely damaged a piece of equipment or supplies, took money from their employer without permission, aforesaid one thing obscene to somebody at workplace to make them feel dangerous and never destroyed property that belong to somebody at work.

On the same line with result Yang \& Diefendorff (2009) ${ }^{(21)}$ who found that CWB is a low-base-rate phenomenon and wasn't discovered often in the organization as nursing staff reported low nervous, scared and irritable negative workplace emotions. Furthermore, result Mackey, Frieder, Perrewé, Gallagher\& Brymer (2015) (22) assumed that the association between experienced mistreatment and tendencies to engage in CWB is complex, and that nursing , perceptions of the workplace play important roles as boundary conditions in this relationship .The more the employees considered that their workplace is valued place in which they work they less engage in CWB.

Additionally, result Chang\& Smithikrai (2010) ${ }^{(23)}$ found that nurses possessing certain personality characteristics were less likely to demonstrate CWB specifically, the higher the level of these characteristics the lower the occurrence of CWB as high agreeableness and self-esteem personality in which employees more open to changes and have high self-esteem in their decisions.

The study results revealed that the mean score of incivility behaviors among nursing staff is low. This result may be due to a majority of nursing staff never exposed to situations in hospital environment as excluding from work related social gathering, removed from tasks so that they were at loss or exposed to offensive or inappropriate jokes.

In this respect, Danque, Serafica, Lane \& Hodge (2014) (24) found that incivility in nursing among the hospital setting may be a concern that has not been explored and difficult to be known and must be researched in a trial to determine normative and practiced 
THE ROLE OF NEGATIVE AFFECTIVITY AND INCIVILITY etc...

$\begin{aligned} & \text { behaviors in the nursing staff } \\ & \text { relationship. }\end{aligned}$
$\begin{aligned} & \text { In contrast to result, Oore et al., } \\ & \text { have larger motivation to engage in } \\ & \text { behaviors that they believe will facilitate } \\ & \text { (2010) (25) found that there are major }\end{aligned}$
them reduce, or cope with these negative
emotions.
contribute to incivility behaviors were workload and job control. These stressors raised nurses' stress levels and contributed to the prevalence of incivility by the nurses who clearly exhibited rude behaviors.

The study results revealed that the mean score of negative affectivity among nursing staff was low. This may be due to good relationship with their collages and they considered that their work is a part of their life and high commitment to their work, so that they experience low hostility, guilty and scared negative attribution.

On the same line with study Baka (2015) ${ }^{\text {(26) }}$ who found that lowest negative affectivity was observed among nurses who reporting low anger suppression and low anxiety suppression.

Furthermore, Cochran (2014) (27) concluded that nurses expose low negative affectivity due to their capability to cope with workplace stressful situations and subsequent changes.

The study results revealed that there was statistically significant positive correlation between negative affectivity and CWB .This result due to large number of nursing staff who had irritable, nervous and upset negative affect engage in behavior to relief this negative affect as they daydream rather than did they work, told people outside the job what a lousy place they work for and start an argument with someone at work.

On the same line with the result Samnani , Salamon \& Singh (2014) ${ }^{(28)}$ who reported that people with high negative affect were a lot of likely to have interaction in CWB as staff with high negative affect tend to understand the

Additionally, Yin (2010) (29) Hong Kong University who reported that there are positive relationship between negative affectivity and CWB based on the proposed emotion-centered model, the external causes generate negative emotions and then employees will engage in CWB to rebalance their negative feelings.

Furthermore, Fida , Paciello, Tramontano, Fontaine, Barbaranelli \& Farnese (2015) ${ }^{(30)}$ found that the a lot of staff react with negative affect to work things that interfere with their work goals and performance, the a lot of they activate cognitive maneuvers that rationalize unethical, wrongful, and deviant behaviors and successively enacting CWB. This enables staff to cutback the emotionally unpleasant condition generated by work stressors.

The study results revealed that there was statistically significant correlation between workplace incivility and total CWB. This result due to nursing staff who exposed to the following situations as questioned about their decisions, paid little attention in their statement or showed little interest in their opinion and took un reasonable workloads or deadlines more than others responded in a negative way to deal with this situations as they daydream rather than did they work ,complained about insignificant things at work and avoided returning a phone call to someone they should call at work.

On the same line with the result Bibi \& Karim (2013) ${ }^{(31)}$ faculty of Balochistan who concluded that there was a positive relationship between workplace incivility and counterproductive work behavior. They thought that workplace incivility as workplace deviant behavior and CWB as an emotional reaction to deal 
with incivility. Completely different individuals respond to and deal with the uncivil settings differently. The severity of their responses ultimately determines the degree to that they cause harm to the organization.

Additionally, welbourne \& Sariol (2017) (32) university of texas - pan American concluded that because incivility is a stressor that is ambiguous and potentially difficult to control , employees may be especially likely to turn to CWB as emotion-focused coping when they experience incivility.Also employees who experienced incivility under conditions of high task interdependence would be more likely to engage in CWB.

Also, Ottinot (2008) ${ }^{(33)}$ University of South Florida found that workplace incivility related positively to counterproductive work behavior towards employees and the organization to relief their negative emotion toward both employees and organization.

\section{Conclusion}

There was statistically significant correlation between counterproductive workplace behavior and both negative affectivity and workplace incivility $(\mathrm{P}<0.05)$ of nursing staff at Main Mansoura University Hospital. The mean score of total counterproductive workplace behavior is lowest followed by workplace incivility and negative affectivity.

\section{Recommendation}

Based on the findings of this study, the following recommendations are suggested:

- Use unstructured interviews which defined as an interview with no set questions are better able to predict which nurses are likely hold characteristics likely to lead to counterproductive behavior, such as nurses who lack self-control.

- Designing new nurses orientation program is an ideal for introducing hospital policies to cope with , defuse and remove uncivil and deviant acts in hospital setting .

- Design and implement policies to reduce the deviant behaviors in the hospital environment . Organizations need to adopt zero tolerance policies that clearly articulate the types of conduct are not acceptable.

- Use of behavioral and outcome based pay incentives this brings into question actions taken by nurses to meet their objectives and make them focus on the way they behave. Thus, making the likelihood of engaging in deviant behaviors lower.

- Incorporate personality based integrity tests in selection process as the most obvious place to start is in selection. But this refers not only to selecting and hiring new employees but in promoting employees to managerial and supervisory roles.

- Use fair, unbiased reward systems based on a predefined criterion that is discussed with nurses and written into contract.

- Appling feedback 360 degree means nurse's performance is measured from totally different views, as peers and supervisors, this offers a lot of data on nurses performance reducing data asymmetry.

- Provide a comfortable physical setting for nursing staff could decrease nurses temptation to be rude and disrespectful that would in turn decrease nurses negative affect and CWB.

- Implement nurses helping programs focusing on teaching nurses the way to manage their negative emotions and higher deal with negative things . Such efforts might ultimately decrease CWB by decreasing the actual experience of negative emotions.

- Nursing managers ought to be positive role models, hold self also 
others, accountable for acceptable behaviors, and reinforce.

\section{References}

[1] Hershcovis, M. S., Turner, N., Barling, J., Arnold, K. A., Dupré, K. E., Inness, M., ... \& Sivanathan, N. (2007). Predicting workplace aggression: a meta-analysis. Journal of applied Psychology, 92(1), 228.

[2]Denollet, J. (2005). DS14: standard assessment of negative affectivity, social inhibition, and Type D personality. Psychosomatic medicine, 67(1), 89-97.

[3] Oginska-Bulik, N. (2005). Emotional intelligence in the workplace: Exploring its effects on occupational stress and health outcomes in human service workers. International journal of occupational medicine and environmental health, 18(2), 167175.

[4] Jeronimus, B. F., Riese, H., Sanderman, R., \& Ormel, J. (2014). Mutual reinforcement between neuroticism and life experiences: A five-wave, 16-year study to test reciprocal causation. Journal of personality and social psychology, 107(4), 751.

[5] Matovic, D., Koch, A. S., \& Forgas, J. P. (2014). Can negative mood improve language understanding? Affective influences on the ability to detect ambiguous communication. Journal of Experimental Social Psychology, 52, 44-49.

[6] Matovic, D., Koch, A. S., \& Forgas, J. P. (2014). Can negative mood improve language understanding? Affective influences on the ability to detect ambiguous communication. Journal of Experimental Social Psychology, 52, 44-49.

[7] Almeida, D. M. (2005). Resilience and vulnerability to daily stressors assessed via diary methods. Current
Directions in Psychological Science, 14(2), 64-68.

[8] .Pearson, C. M., Andersson, L. M., \& Porath, C. L. (2005). Workplace incivility.

[9] Reio Jr, T. G., \& Ghosh, R. (2009). Antecedents and outcomes of workplace incivility: Implications for human resource development research and practice. Human Resource Development Quarterly, 20(3), 237-264.

[10] Chappell, D., \& Di Martino, V. (2006). Violence at work. International Labour Organization.

[11] Spector, P. E., \& Fox, S. (2002). An emotion-centered model of voluntary work behavior: Some parallels between counterproductive work behavior and organizational citizenship behavior. Human resource management review, 12(2), 269-292.

[12] Spector, P. E., Fox, S., Penney, L. M., Bruursema, K., Goh, A., \& Kessler, S. (2006). The dimensionality of counterproductivity: Are all counterproductive behaviors created equal?. Journal of vocational behavior, 68(3), 446-460.

[13[ Penney, L. M., \& Spector, P. E. (2005). Job stress, incivility, and counterproductive work behavior (CWB): The moderating role of negative affectivity. Journal of Organizational Behavior: The International Journal of Industrial, Occupational and Organizational Psychology and Behavior, 26(7), 777-796.

[14] Hershcovis, M. S., Turner, N., Barling, J., Arnold, K. A., Dupré, K. E., Inness, M., ... \& Sivanathan, N. (2007). Predicting workplace aggression: a meta-analysis. Journal of applied Psychology, 92(1), 228.

[15] Dalal, R. S., Lam, H., Weiss, H. M., Welch, E. R., and Hulin, C. L 
(2009): A within-person approach to work behavior and performance Concurrent and lagged citizenshipcounter productivity associatand dynamic relationships with affect and overall job performance.

Academy of Management Journal, 52(5), Pp1051-1066.41.

[16] Brans, K., Koval, P., Verduyn, P., Lim, Y. L., \& Kuppens, P. (2013). The regulation of negative and positive affect in daily life. Emotion, 13(5), 926.

[17] Watson, D., \& Clark, L. A. (1999). The PANAS-X: Manual for the positive and negative affect scheduleexpanded form.

[18] Penney, L. M., \& Spector, P. E. (2005). Job stress, incivility, and counterproductive workplace behavior (CWB): The moderating role of negative affectivity. Journal of Organizational Behavior, 26(5), 777-796.

[19] Spector, P. E., Fox, S., Penney, L. M., Bruursema, K., Goh, A., \& Kessler, S. (2006). The dimensionality of counter productivity: Are all counterproductive behaviors created equal? Journal of Vocational Behavior, 68 (3), 446-460.

[20] Dilchert, S., Ones, D. S., Davis, R. D., \& Rostow, C. D. (2007). Cognitive ability predicts objectively measured counterproductive work behaviors. Journal of Applied Psychology, 92(3), 616.

[21] Yang, J., \& Diefendorff, J. M. (2009). The relations of daily counterproductive workplace behavior with emotions, situational antecedents, and personality moderators: A diary study in Hong Kong. Personnel Psychology, 62(2), 259-295.

[22] Mackey, J. D., Frieder, R. E., Perrewé, P. L., Gallagher, V. C., \& Brymer, R. A. (2015). Empowered employees as social deviants: The role of abusive supervision. Journal of Business and Psychology, 30(1), 149-162.

[23] Chang, K., \& Smithikrai, C. (2010). Counterproductive behaviour at work: an investigation into reduction strategies. The International Journal of Human Resource Management, 21(8), 1272-1288.

[24] Danque, C. T., Serafica, R., Lane, S. H., \& Hodge, M. A. (2014). Incivility in the hospital environment: the nurse educator-staff nurse relationship. Journal for nurses in professional development, 30(4), 185-189.

[25] Gilin Oore, D. E. B. R. A., Leblanc, D., Day, A., Leiter, M. P., Spence Laschinger, H. K., Price, S. L., \& Latimer, M. (2010). When respect deteriorates: incivility as a moderator of the stressor-strain relationship among hospital workers. Journal of Nursing Management, 18(8), 878888.

[26] Baka, Ł. (2015). How do negative emotions regulate the effects of workplace aggression on counterproductive work behaviours? Polish Psychological Bulletin, 46(3), 326-335.

[27]Cochran, M. (2014). Counterproductive work behaviors, justice, and affect: A meta-analysis.

[28] Samnani, A. K., Salamon, S. D., \& Singh, P. (2014). Negative affect and counterproductive workplace behavior: The moderating role of moral disengagement and gender. Journal of Business ethics, 119(2), 235-244.

[29] Yin, L. C. (2010). Emotional intelligence as a moderator in the relationship between negative emotions and counterproductive work behaviors.

[30] Fida, R., Paciello, M., Tramontano, C., Fontaine, R. G., Barbaranelli, C., \& Farnese, M. L. (2015). An 
integrative approach to understanding counterproductive work behavior:

The roles of stressors, negative emotions, and moral disengagement. Journal of Business Ethics, 130(1), 131-144.

[31] Bibi, Z., Karim, J., \& ud Din, S. (2013). Workplace incivility and counterproductive work behavior: Moderating role of emotional intelligence. Pakistan Journal of Psychological Research, 28(2).

[32] elbourne, J. L., \& Sariol, A. M. (2017). When does incivility lead to counterproductive work behavior? Roles of job involvement, task interdependence, and gender. Journal of occupational health psychology, 22(2), 194.

[33]Ottinot, R. C. (2008).

The development and validation of the perceived workplace civility climate scale. 